\title{
Dívida Pública, Déficit Público e A rrecadação no Brasil: uma análise da tensão institucional (1995 a 2007)
}

\author{
Renato Vaz Garcia* \\ Elton Eustaquio Casagrande**
}

Resumo: 0 debate relativo à política fiscal com destaque para a dívida pública, matéria deste artigo, tornou-se de grande importância na política econômica brasileira. Com a aprovação da Lei de Responsabilidade F iscal, no ano de 2000, e a nova estrutura fiscal que se consolidou nos últimos anos há uma tendência de neutralidade, no sentido de que o Estado não utilizaria seu orçamento para compensar a redução do gasto agregado privado. 0 controle dos gastos, a política de melhoria do perfil e a composição da dívida pública interna e a busca pela redução do déficit público são analisados entre 1995 e 2007. O objetivo é explorar a relação tensa que foi construída a partir das decisões de financiamento do setor público que, por sua vez, podem comprometer a própria sustentabilidade e o desenvolvimento econômico do País.

Palavras-chave: Dívida Pública, Política Fiscal, Desenvolvimento.

Abstract: The debate on fiscal policy and its connection with public debt continue to be important to the Brazilian economy. The Fiscal Responsibility Law, approved in 2000 by the National Congress, and the new directives of the National Treasury, which established rules to avoid discretionary policy, reduced the impact of the fiscal policy on aggregate demand and capital formation. We discuss in this paper the fiscal policy from 1995 to 2007 and we argue that the new directives were not sufficient to strengthen the public budget and may have a negative effect on the economic development of the country.

Keyw ords: Public Debt, Fiscal Policy, Development.

J EL Classification: E12, E62, H63

\section{Introdução}

O debate relativo à política fiscal com destaque para a dívida pública, matéria deste artigo, tornou-se de grande importância na

\footnotetext{
* Mestre em Economia pelo Programa de Pós-Graduação em Economia da Faculdade de Ciências e Letras - Campus de Araraquara-UNESP. E-mail: renato2405@yahoo.com.br

** Prof. do Departamento de Economia da Faculdade de Ciênciase Letras - Campus de AraraquaraUNESP. E-mail: elton.ec@itelefonica.com.br.
} 
política econômica brasileira. Desde os grandes projetos de investimento, impulsionados pelo Estado durante as décadas de 1950 até o início da década de 1970, a política de gastos públicos e sua forma de financiamento desempenharam um importante papel no crescimento econômico do País.

Dentro da perspectiva de uma economia monetária, ${ }^{1}$ a política fiscal teria a função de incrementar a demanda agregada e de influenciar as expectativas de firmas e de consumidores favorecendo a redução da incerteza. Por meio de uma política adequada de gastos públicos, e não de déficits públicos persistentes, o setor público teria a disponibilidade de intervir na atividade econômica, com o objetivo de criar o ambiente favorável para a atuação do setor privado (CARVALHO, 2007).

Após as décadas de 1970 e 1980, juntamente com o enfraquecimento da política econômica keynesiana, a política fiscal passou a ser questionada, em particular, em função do crescimento do déficit público e da inflação. Nos anos 1990, com as intervenções do Fundo Monetário Internacional (FMI), a política fiscal foi direcionada pelos governos a fim de garantir o equilíbrio financeiro do setor público, em detrimento de outros objetivos da política econômica. As intervenções do FMI, principalmente em economias em desenvolvimento, buscaram a sustentabilidade financeira das contas públicas com a geração de elevados superávits primários. ${ }^{2} 0$ objetivo consistia em garantir o cumprimento das obrigações financeiras do setor público.

No Brasil, na década de 2000, a política fiscal tem sido reformada em termos de controle e de transparência dos gastos públicos, de arrecadação tributária e de estabelecimento de metas fiscais, principalmente a partir da aprovação da Lei de Responsabilidade Fiscal (LRF). Na nova estrutura da política fiscal que se consolidou, há uma tendência de neutralidade, no sentido de que o Estado não utilizaria seu orçamento para compensar a redução do gasto agregado privado.

A geração de superávits primários persistentes se tornou a principal expressão do controle das contas públicas, porém, a estrutura de gastos públicos por um lado, e o perfil de endividamento público

\footnotetext{
Em uma economia monetária da produção, a moeda teria um papel por si só, o que afeta motivos e decisões dos agentes. Dessa forma, o processo econômico não poderia ser previsto no curto ou no longo prazo, sem o conhecimento prévio do comportamento da moeda (KEYNES, 1971, v.13).

2 Receitas públicas menos despesas públicas não financeiras.
} 
- concentrado em papéis de curto prazo e indexado a taxa básica de juros, por outro, tornou a noção de superávit primário menos convincente para avaliar a prática fiscal.

A composição de endividamento desfavorável e 0 alto percentual dos gastos públicos em despesas financeiras restringiram as intervenções do governo e sustentaram a geração de resultados nominais deficitários. ${ }^{3}$

Defendida como virtuosa à economia, a política fiscal no Brasil recente transporta ao longo dos anos uma relação tensa entre déficit público e estrutura de financiamento, a partir de uma alta carga tributária e da geração de elevados superávits primários. Há uma inconsistência em busca do equilíbrio financeiro do setor público em função da estrutura de financiamento desfavorável em termos de custo e perfil de dívida, por um lado, e manutenção de déficits fiscais, no conceito nominal, por outro.

A partir dessas relações, o artigo tem por objetivo discutir a política fiscal no Brasil, entre 1995 e 2007, e explorar a relação tensa que foi construída a partir das decisões de financiamento do setor público que, por sua vez, podem comprometer a própria sustentabilidade e o desenvolvimento econômico do País.

0 artigo está dividido em quatro seções, além desta introdução. $\mathrm{Na}$ primeira seção, discutimos a relação entre resultados fiscais segundo a LRF; na seção seguinte, dedicamo-nos à análise da dívida pública e seu impacto orçamentário; e, finalmente, abordamos a política fiscal sob restrições financeiras persistentes. Na conclusão, exploramos a relação tensa imposta pelas condições de endividamento do setor público.

\section{Resultados fiscais pós-plano real e lei de responsabilidade fiscal}

O Plano Real permitiu que a economia alcançasse as condições da estabilidade dos níveis de preços. A diminuição do imposto inflacionário proporcionou um crescimento do consumo, notadamente em bens não duráveis. ${ }^{4}$ Apesar desse êxito em termos de queda da inflação, a taxa de crescimento econômico ficou muito aquém das expectativas dos formuladores de política econômica e, o mais grave, a taxa de desemprego sofreu uma elevação significativa ao longo dos anos seguintes (colunas 2 e 3 da Tabela 1).

\footnotetext{
${ }^{3}$ Receitas públicas menos despesas públicas inclusive financeiras.

${ }^{4}$ Ver Ferrari Filho (2001).
} 
Quanto à política fiscal, vemos uma contradição. O déficit público aumentou sem a contrapartida do crescimento do produto. A diferença entre as receitas e despesas totais do setor público, subtraído pela atualização monetária da dívida pública (resultado operacional), ${ }^{5}$ passou de um superávit de 1,57\% do PIB, em 1994 para um déficit de $7,4 \%$ do PIB, em 1998. Além disso, durante a implantação do Plano Real, a dívida pública mobiliária federal interna (DPMFi), composta por títulos públicos em poder do mercado, ${ }^{6}$ cresceu de $11 \%$ do PIB em 1994 para 40\% do PIB em 1998. A deterioração das contas públicas e o salto de crescimento da dívida mobiliária devem ser compreendidos sob o âmbito das políticas implantadas durante a fase inicial do Plano Real.

Tabela 1 - Indicadores Macroeconômicos e Dívida Mobiliária em Poder do Público - Brasil (1994-2006)

\begin{tabular}{c|c|c|c|c}
\hline A no & $\begin{array}{c}\text { Crescimento do } \\
\text { PIB (\%) }\end{array}$ & $\begin{array}{c}\text { Taxa de Desemprego A berta } \\
\text { (média anual em \%)* }\end{array}$ & IG P (\% dez.) dez.) & DPM Fi/ PIB** \\
\hline 1994 & 5,33 & 5,1 & 1093,9 & $11,60 \%$ \\
\hline 1995 & 4,22 & 4,6 & 14,8 & $16,96 \%$ \\
\hline 1996 & 2,15 & 5,4 & 9,3 & $24,69 \%$ \\
\hline 1997 & 3,38 & 5,7 & 7,5 & $32,33 \%$ \\
\hline 1998 & 0,04 & 7,6 & 1,7 & $40,23 \%$ \\
\hline 1999 & 0,25 & 7,6 & 20 & $42,87 \%$ \\
\hline 2000 & 4,31 & 7,1 & 9,8 & $46,19 \%$ \\
\hline 2001 & 1,31 & 6,2 & 10,4 & $50,55 \%$ \\
\hline 2002 & 2,66 & 11,7 & 26,4 & $38,51 \%$ \\
\hline 2003 & 1,15 & 12,3 & 7,7 & $41,81 \%$ \\
\hline 2004 & 5,71 & 11,5 & 12,1 & $39,14 \%$ \\
\hline 2005 & 2,94 & 9,8 & 1,2 & $45,33 \%$ \\
\hline 2006 & 3,7 & 10 & 3,8 & $47,08 \%$ \\
\hline
\end{tabular}

* Em 2002, há uma mudança na metodologia do cálculo da base de referência do índice de desemprego, o que proporcionou o aumento considerável de tal índice.

** Deflacionado pelo IGP-DI.

Fonte: IPEADATA, 2007.

50 conceito de déficit público utilizado diz respeito às necessidades de financiamento do setor público (NFSP), em acordo com o Fundo Monetário Internacional (FMI).

6 O conceito de DPMFi, no Brasil, refere-se ao passivo em títulos emitidos pelo Tesouro Nacional e pelo Banco Central, que, a partir de 2002, em acordo com a LRF, ficou impedido de emitir títulos primários. 
A abertura comercial e a liberalização financeira, no início dos anos noventa, passaram a cumprir um importante papel na queda da inflação e na sua manutenção em níveis relativamente baixos. 0 elevado diferencial entre as taxas de juros interna e externa possibilitou uma significativa entrada de capital externo, o que desencadeou o aumento do volume de reservas internacionais e o uso da ancoragem cambial. ${ }^{7}$ No entanto, a fim de sustentar o financiamento do Balanço de Pagamentos e a estabilidade inflacionária, criou-se uma armadilha cambial por meio de um aumento da dívida pública. De acordo com Ferrari Filho (2002, p.19), a armadilha em torno da dívida pública constitui:

[...] a situação na qual a sobrevalorização da taxa de câmbio, aliada à abertura comercial, resultou em recorrentes e crescentes desequilíbrios do balanço de pagamentos em transações correntes. Esses, por sua vez, foram financiados pelo ingresso de capital internacional, predominantemente volátil, atraído pela elevada taxa de juros doméstica. A contrapartida da elevação da taxa de juros foi o crescimento da dívida pública, pressionando, assim, o desequilíbrio do setor público.

Além disso, ao manter os juros elevados e a atração de capital externo, o governo intensificou o uso de políticas de esterilização, a fim de manter a liquidez da economia sob controle, por meio do lançamento de títulos públicos e do crescimento da DPMFi. ${ }^{8}$ Com essa atuação da política monetária, o custo de rolagem da dívida pública cresceu, visto que a taxa de juros internacional, recebida pelo Tesouro Nacional pela aplicação das reservas cambiais, é consideravelmente inferior aos juros pagos internamente sobre os títulos públicos emitidos. ${ }^{9}$

Além de contribuir para o aumento do endividamento público, a elevada taxa de juros adotada durante o período causou um impacto imediato sobre os encargos financeiros da dívida pública, e contribuiu para a deterioração das necessidades de financiamento do setor público (NFSP).

7 Ver Franco (1995) e Bacha (1997).

8 As políticas de esterilização dizem respeito à seguinte situação: com a entrada maciça de capitais externos, eleva-se a base monetária e cria-se uma tendência de queda na taxa de juros. Para evitar essa queda e manter a inflação sob controle, o governo interfere no mercado por meio da venda de títulos públicos com o objetivo de resgatar o excesso sobre a base monetária.

9 Atualmente, a política de acumulação de reservas por parte do Banco Central vem recebendo críticas, justamente por seu elevado custo fiscal, representado pela diferença entre o patamar de juros internacionais, de cerca de $4 \%$, e a taxa de juros doméstica, na casa dos $13 \%$ ao ano em termos nominais. 
As despesas reais com o pagamento de juros sobre a dívida pública (coluna 5 da Tabela 2) aumentaram de 4,07\% em 1994 para 7,42\% em relação ao PIB em 1998. Diante desse cenário, Tavares (1998) aponta que as despesas com juros se apresentaram como o principal vetor do déficit público durante o período de implantação do Plano Real, o que impôs um maior desequilíbrio financeiro ao setor público. Carneiro (2002) acrescenta que o elevado peso dos gastos financeiros e a consequente geração de déficit público não proporcionaram um aumento da demanda agregada, mas sim um aumento da transferência de renda em benefício da riqueza financeira privada.

A pesar da alta participação dos encargos financeiros nos déficits operacional e nominal, o resultado primário também se deteriorou no período inicial do Plano Real. Assim, excetuando o pagamento das despesas financeiras, o déficit público se elevou como resultado de um aumento dos gastos públicos não financeiros, em particular aqueles relativos aos benefícios previdenciários. ${ }^{10}$

A partir de 1999, juntamente com a adoção do regime de metas de inflação, ${ }^{11}$ o novo regime de metas fiscais e a LRF , 12 tiveram como objetivos o controle e a redução do déficit público, bem como a garantia dos pagamentos dos encargos financeiros da dívida pública. Nessa direção, em conjunto com o FMI, o governo aplica um ajuste fiscal por meio da adoção de metas e limites para as necessidades de financiamento do setor público. ${ }^{13}$ As medidas de ajuste contemplavam, principalmente, a estabilidade da dívida pública e a divulgação de metas para a geração de superávits primários, no princípio, para o período 1999-2001. ${ }^{14}$ As medidas resultaram em aumento dos superávits primários e em redução dos déficits nominais, apesar da sua manutenção em torno de 3\% a 4\% do PIB (Tabela 2).

${ }^{10}$ Ver Castro et al. (2006).

${ }^{11}$ Diante do regime de metas de inflação, a política monetária passa a responder como principal instrumento de política econômica. Nesse sentido, o Banco Central, a partir de algum formato da Regra de Taylor, administra a taxa de juros nominal em prol das metas de inflação estabelecidas. 0 regime de metas de inflação foi adotado formalmente no País a partir de junho de 1999. Para detalhes sobre o regime de metas de inflação no Brasil, ver Arestis, Paula e Ferrari Filho (2006).

12 A LRF foi implantada em acordo com o FMI e teve, como referencial, o Tratado de Maastricht de 1992, na União Européia; o Fiscal Responsability Act de 1994, na Nova Zelândia e o Budget Enforcemente Act de 1990, nos Estados Unidos.

${ }^{13}$ Cabe destacar, que, em meados da década de 90, o governo já vinha adotando medidas no sentido de possibilitar um ajuste fiscal, através do Plano de Ação Imediata (PAI) e do Fundo Social de Emergência (FSE), que possibilitaram a desvinculação de receitas da União. Para detalhes sobre o PAI e sobre o FSE, ver Castro (2005).

${ }^{14} \mathrm{Em}$ virtude da desvalorização cambial de janeiro de 1999, as metas, que haviam sido acordadas em 1998, foram revistas para cima, uma vez que a desvalorização provocou um impacto direto sobre a dívida pública indexada ao câmbio, conforme visto anteriormente. 
Aprovada em 2000, a LRF instituiu uma mudança cultural dentro das instituições públicas. Dentre as principais medidas adotadas com a lei, destacam-se: a adoção de metas fiscais, limites para o gasto com despesa com pessoal, limites para o endividamento público, regras de transparência e imposição de penalidades para os administradores públicos que infringissem as medidas. ${ }^{15}$

Notadamente em relação às metas fiscais, a LRF procurou constituir um maior equilíbrio entre as receitas e despesas do setor público. Através do Anexo de Metas Fiscais da Lei de Diretrizes Orçamentárias (LDO), ${ }^{16}$ a Lei passou a exigir o estabelecimento de metas referentes a receitas, despesas, resultado nominal, resultado primário e montante da dívida pública para o ano corrente e para os dois anos seguintes (Quadro 1). Além disso, de acordo com a lei, o Anexo de Metas deveria conter a avaliação do cumprimento das metas no ano anterior, os demonstrativos das metas com metodologia e memória de cálculo, a evolução do patrimônio líquido com origens e aplicação de recursos e a avaliação financeira e atuarial.

Tabela 2 - Necessidade de Financiamento do Setor Público Brasil (1991-2006)*

\begin{tabular}{c|c|c|c|c|c|c}
\hline A no & $\begin{array}{c}\text { Déficit (-) ou } \\
\text { Superávit (t) } \\
\text { Primário - em \% } \\
\text { do PIB (A) }\end{array}$ & $\begin{array}{c}\text { Juros N ominais - } \\
\text { em \% do PIB (B) }\end{array}$ & $\begin{array}{c}\text { Juros N ominais - } \\
\text { em R\$ milhóes }\end{array}$ & $\begin{array}{c}\text { Juros Reais } \\
- \text { em \% do } \\
\text { PIB (C) }\end{array}$ & $\begin{array}{c}\text { Déficit (-) ou } \\
\text { Superávit (t) } \\
\text { Nominal - } \\
\text { em \% do PIB } \\
(A+B)\end{array}$ & $\begin{array}{c}\text { Déficit (-) ou } \\
\text { Superávit (t) } \\
\text { O peracional - em } \\
\% \text { do PIB }(A+C)\end{array}$ \\
\hline 1991 & 2,71 & 29,46 & 17,76 & 2,9 & $-26,75$ & $-0,19$ \\
\hline 1992 & 1,58 & 47,33 & 303,86 & 3,32 & $-45,75$ & $-1,74$ \\
\hline 1993 & 2,18 & 67,01 & 9447,46 & 2,98 & $-64,83$ & $-0,8$ \\
\hline 1994 & 5,64 & 32,61 & $112,381,79$ & 4,07 & $-26,97$ & 1,57 \\
\hline 1995 & 0,26 & 7,54 & $48,750,31$ & 5,26 & $-7,28$ & -5 \\
\hline
\end{tabular}

${ }^{15}$ A LRF passaria a gerar elevadas punições à prática indisciplinar do administrador público, conforme previsto na Lei de Crimes Fiscais (LCF), aprovada no mesmo ano da LRF. As infrações sujeitas a punições ocorreriam em casos da não publicação de relatórios de acordo com a lei, do não cumprimento aos limites de despesas e de endividamento, da realização de operações de crédito em desacordo com a lei, dentre outros casos. As punições dependeriam do ato de infração e poderiam chegar a quatro anos de reclusão, em casos de descumprimento das medidas relativas às despesas com pessoal.

${ }^{16}$ Como parte da elaboração do orçamento do governo, torna-se relevante a relação entre o Plano Plurianual (PPA), a Lei de Diretrizes Orçamentárias (LDO) e a Lei Orçamentária Anual (LOA). O PPA é elaborado pelo executivo e compreende as metas do governo federal para um período de quatro anos. Em seguida, é elaborada a LDO que estabelece as metas e prioridades do governo para o ano seguinte. A LDO compreende o Anexo de Metas Fiscais, com as metas para o exercício seguinte e indicação para os dois anos posteriores. Por fim, a partir da LDO e das prioridades designadas no PPA, elabora-se a LOA, que disciplina as ações do governo federal durante o ano (BRASIL, 2007b). 


\begin{tabular}{l|c|c|c|c|c|c}
\hline 1996 & $-0,1$ & 5,77 & $45.001,48$ & 3,3 & $-5,87$ & $-3,4$ \\
\hline 1997 & $-0,96$ & 5,15 & $44.922,64$ & 3,35 & $-6,11$ & $-4,31$ \\
\hline 1998 & 0,02 & 7,95 & $72.596,02$ & 7,42 & $-7,93$ & $-7,4$ \\
\hline 1999 & 3,23 & 13,21 & $127.244,97$ & 6,64 & $-9,98$ & $-3,41$ \\
\hline 2000 & 3,47 & 7,95 & $87.442,24$ & 4,64 & $-4,48$ & $-1,17$ \\
\hline 2001 & 3,36 & 8,11 & $105.625,03$ & 4,64 & $-4,76$ & $-1,28$ \\
\hline 2002 & 3,55 & 12,9 & $190.665,73$ & 3,54 & $-9,36$ & 0,01 \\
\hline 2003 & 3,89 & 7,21 & $122.487,98$ & 4,7 & $-3,31$ & $-0,81$ \\
\hline 2004 & 4,17 & 6,43 & $124.920,97$ & 2,34 & $-2,26$ & 1,83 \\
\hline 2005 & 4,36 & 7,1 & $152.591,30$ & 6,58 & $-2,75$ & $-2,22$ \\
\hline 2006 & 3,88 & 6,79 & $157.804,26$ & 5,26 & $-2,91$ & $-1,38$ \\
\hline
\end{tabular}

*Com desvalorização cambial sobre estoque da dívida mobiliária interna..

Fonte: IPEADATA, 2007.

Quadro 1 - Lei de Responsabilidade Fiscal e Metas Fiscais - Brasil
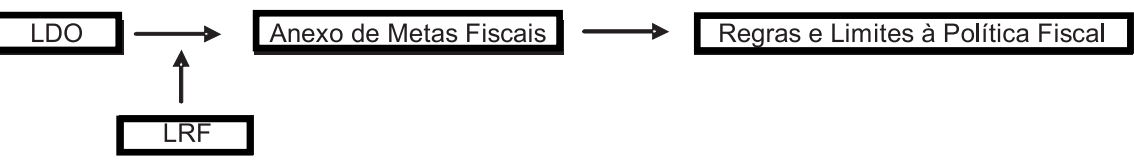

Fonte: Elaboração própria.

Com a LRF, a política fiscal se caracterizou por uma maior disciplina e transparência em relação às contas públicas. De acordo com Anexo de Metas Fiscais da LDO de 2007:

O objetivo primordial da política fiscal do governo é promover a gestão equilibrada dos recursos públicos, de forma a assegurar a manutenção da estabilidade econômica e o crescimento sustentado. A política fiscal busca criar as condições necessárias para a queda sustentável das taxas de juros, a melhora do perfil da dívida pública e a redução gradual do endividamento público líquido em relação ao PIB. Também é compromisso da política fiscal do governo promover a melhoria dos resultados da gestão fiscal, com vistas a implementar políticas so ciais distributivase tornar viáveis os investimentos em infraestrutura (BRASIL, 2007a).

Além da transparência, a combinação da respectiva lei com a LDO significou um novo arranjo institucional que limitou a realização 
dos gastos discricionários. O novo arranjo, apesar de impor maior regulamentação à política fiscal, forçando um maior ajuste fiscal, limitou-se ao tratamento dos gastos públicos não financeiros, de maneira que os elevados pagamentos com encargos financeiros da dívida pública se mantiveram durante o período posterior à lei. Conforme esclarece Khair (2006, p.353):

A LRF cuida apenas da parte não-financeira das despesas públicas. Considerando que o componente financeiro representa importante parcela do ônus fiscal do país, é necessário que o mesmo seja também considerado para se ter um equilíbrio fiscal saudável das contas públicas brasileiras.

Dessa forma, a política de taxa de juros elevada, sustentada desde a adoção do Plano Real, ainda contribui para o alto custo da dívida pública, que, por sua vez, dificulta a implantação de um ajuste fiscal duradouro. A pesar dos elevados cortes de gastos públicos e da consequente obtenção de superávits primários, o peso das despesas financeiras se manifesta na geração de resultados nominais deficitários. Nesse cenário, a aprovação da LRF se torna incoerente com o próprio princípio da responsabilidade fiscal. A partir do momento que o ajuste fiscal não tem como foco um dos principais componentes dos gastos públicos, o debate sobre o ajuste das contas públicas se torna incoerente e pouco eficaz. Não obstante a importância sobre a imposição de regras e limites para os gastos discricionários, principalmente, no caso brasileiro em que o "populismo" fiscal, muitas vezes, se fez presente, a LRF deixa de atacar o grande entrave das contas públicas, representado pelo atual patamar de endividamento público e seu elevado custo fiscal.

\section{Dívida pública: composição e perfil entre 1995 e 2007}

A manutenção de resultados fiscais deficitários e os altos desembolsos financeiros do setor púbico se mostram relacionados à atual estrutura da dívida pública no País. Na fase inicial do Plano Real, entre 1994 e 1998, o aumento do patamar de endividamento público foi acompanhado pela deterioração de seu perfil e composição, especialmente a partir de um cenário de crises em economias em desenvolvimento. ${ }^{17}$ Diante de um cenário de crise, os investidores exigiam um montante maior de títulos públicos pós-fixados, indexados à taxa de câmbio e, principalmente, à taxa de juros básica - Selic -, cuja

\footnotetext{
${ }^{17}$ Entre 1994 e 1998, se observa a crise do México, da Ásia e da Rússia.
} 
participação relativa na DPMFi passou de 37,8\%, em 1995, para 69,1\%, em 1998 (Gráfico 1). ${ }^{18}$ Assim, frente às recorrentes crises internacionais o governo emite papéis em condições bastante desfavoráveis ao setor público, incrementa o seu custo fiscal e a deterioração das contas públicas.

A partir de 1999, porém, é possível notar novas alterações em relação à composição de endividamento público, conforme apresenta o Gráfico 1. O patamar da dívida pública indexada à taxa de câmbio vinha mantendo um desempenho estável, até que, em 2001 e em 2002, tais títulos iniciam uma trajetória decrescente como resultado de sua substituição por papéis prefixados e indexados a índices de preços.

Já a composição da dívida mobiliária indexada à taxa básica de juros Selic, manteve-se elevada. Em 2005, tais papéis iniciam uma trajetória de queda mais evidente, interrompida, porém, entre 2006 e 2007. A sustentação dos títulos indexados à Selic se deve, em grande parte, a melhor remuneração aos títulos dada pela política do governo, que, nas circunstâncias que se seguiram à eleição presidencial, instituíram uma de taxa de juros real, cuja magnitude não encontra racionalidade.

Sicsú e Vidotto (2007) esclarecem que, diante desse quadro, a política fiscal no Brasil passa a ter um papel de subordinação à política monetária, uma vez que, todo momento em que o Banco Central modifica sua política de juros, afeta, diretamente, os custos do Tesouro com encargos da dívida pública. Nesse contexto, Sicsú e Vidotto (2007) acrescentam que a redução das taxas de juros no Brasil poderia reduzir, de maneira drástica, os custos com despesas financeiras, e assim, alterar a composição de gastos do setor público em prol de uma política fiscal mais coerente com o crescimento econômico.

[...] uma redução da taxa de juros no Brasil para patamares praticados extensivamente no mundo poderia reduzir drasticamente as despesas fiscais financeiras. Assim, dezenas de bilhões de reais poderiam ser alocados para sustentar uma administração fiscal plena, ou seja, que sinalize a possibilidade permanente de que o governo honraria os seus compromissos financeiros e, ao mesmo tempo, manteria uma elevada taxa de crescimento da economia sustentada por uma política fiscal de gastos públicos (SICSÚ; VIDOTTO, 2007, p.119).

\footnotetext{
${ }^{18}$ Os títulos indexados ao câmbio dizem respeito às Notas do Tesouro Nacional - série D (NTN-D) e os títulos indexados a Selic dizem respeito às Letras Financeiras do Tesouro (LFTs).
} 
Gráfico 1 - Composição da DPMFi em poder do público por indexador entre 1995-2007 - Brasil (participação percentual)

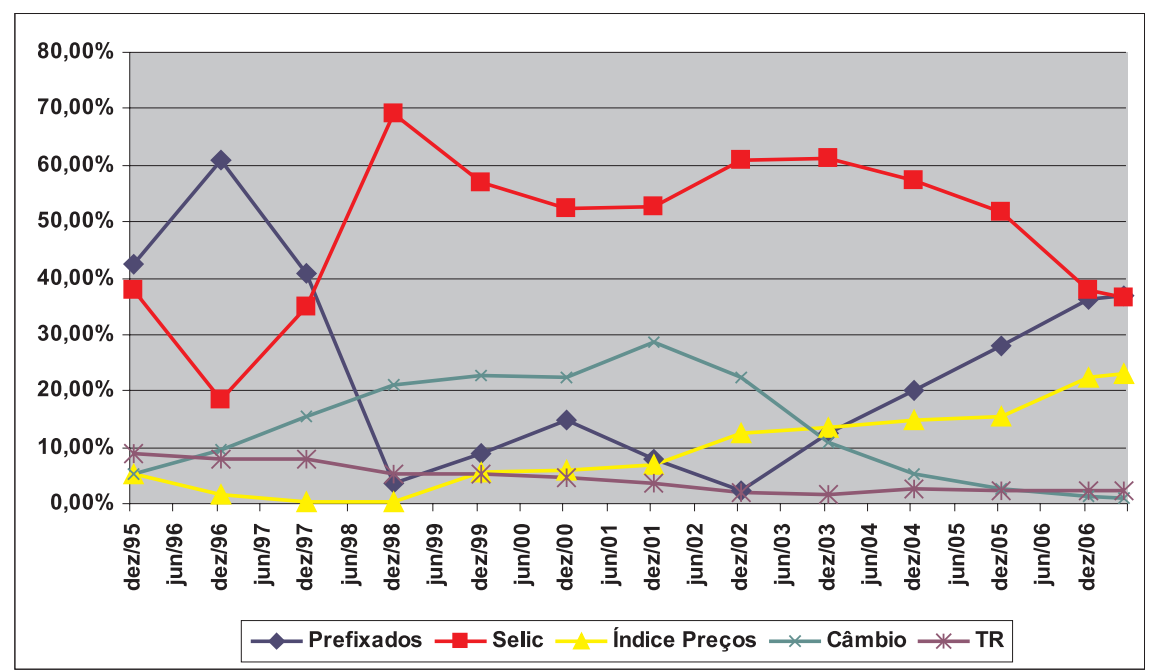

Fonte: Secretaria do Tesouro Nacional (BRASIL, 2007c, 2007d) e Banco Central do Brasil (2007).

Por sua vez, o aumento da participação de títulos prefixados, emitidos com um patamar de juros elevados e com prazos de vencimento relativamente curtos, os quais variavam entre 6 e 24 meses, ${ }^{19}$ impuseram uma restrição às contas públicas para períodos subsequentes. A elevada taxa de juros definida em $t$ transferiria para $t_{+1}$ uma rigidez para baixo da própria taxa, independentemente das condições macroeconômicas, que, se melhoraram, não puderam ser observadas pelo comportamento da taxa de juros. Assim sendo, se a percepção de risco sobre a situação macroeconômica brasileira tornava-se melhor depois de 2002, não seria adequado ampliar a participação desses títulos diante de uma perspectiva de queda na taxa de juros básica - Selic.

Quanto ao prazo médio de endividamento, a DPMFi apresentou uma trajetória lenta de alongamento, notadamente a partir de 2006 (Gráfico 2). A estratégia de alongamento do prazo médio de endividamento foi favorecida pelo aumento da participação de investidores estrangeiros no mercado de títulos públicos. 0 percentual de

\footnotetext{
${ }^{19}$ Os principais títulos prefixados emitidos pelo Tesouro referem-se às Letras do Tesouro Nacional (LTN) e às Notas do Tesouro Nacional - série F (NTN-F).
} 
participação aumentou de 0,9\%, em fevereiro de 2006, para 3,6\% em março de 2007, favorecido por medidas de isenção fiscal para aplicadores estrangeiros. ${ }^{20} \mathrm{~A}$ parcela de títulos incorporada por investidores estrangeiros refere-se a papéis prefixados de longo prazo e indexados a índices de preços. ${ }^{21}$ Nesse contexto, Moura (2007) afirma que as medidas possibilitariam o surgimento de um mercado de títulos públicos prefixados de longo prazo..$^{22}$

Gráfico 2 - Prazo Médio da DPMFi em poder do público - Brasil (em anos)

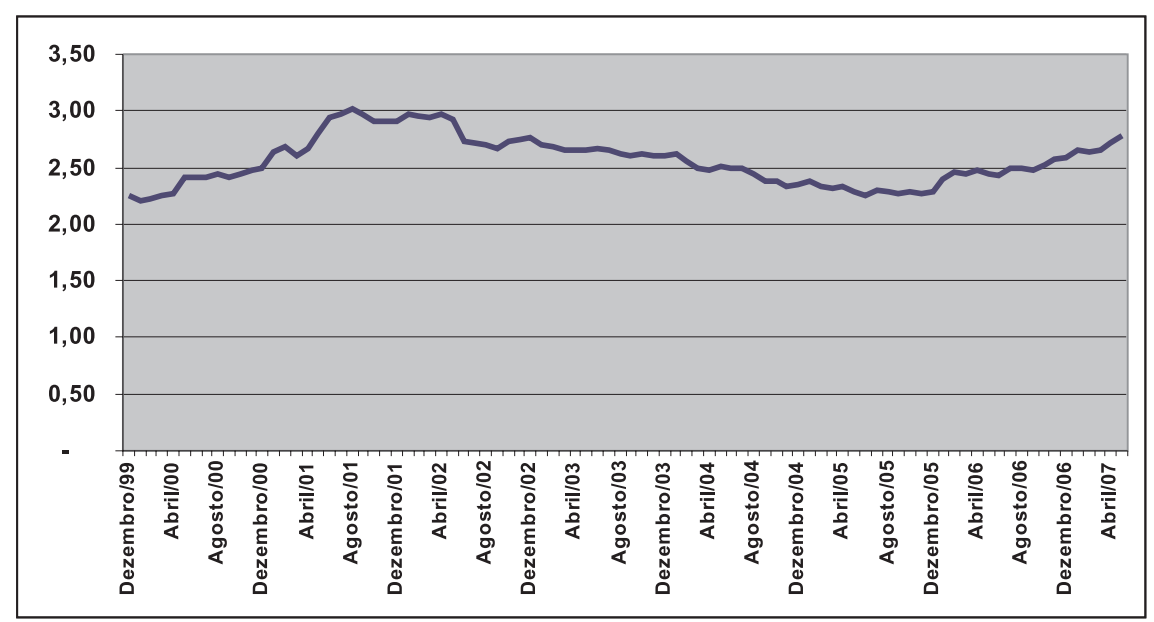

Fonte: Secretaria do Tesouro Nacional (BRASIL, 2007c, 2007d)) e Banco Central do Brasil (2007).

Se há um maior compromisso do governo federal com a adoção de medidas que busque melhorar a composição e o perfil da

\footnotetext{
${ }^{20}$ A partir de fevereiro de 2006, o governo passou a oferecer incentivos fiscais a investidores estrangeiros que detenham papéis brasileiros, por meio da isenção de imposto de renda sobre a rentabilidade e de CPMF para as migrações de aplicação em ações para títulos públicos. Entretanto, de acordo com Guilherme Pedras, coordenador-geral da dívida pública da secretaria do Tesouro Nacional, o percentual de estrangeiros na dívida pública ainda é baixo, em comparação com México (entre $10 \%$ e $12 \%)$, Turquia (17\%) e Hungria (30\%). Ver Ribeiro ( 2007).

${ }^{21}$ Os principais papéis indexados a índices de preços são as Notas do Tesouro Nacional - série B (NTN-B), indexadas ao Índice Nacional de Preços ao Consumidor Amplo (IPCA).

22 Moura (2007) acrescenta que a medida possibilitaria maior eficácia da política monetária, por meio do aumento de papéis prefixados.
} 
dívida pública, de modo a aperfeiçoar o mercado de títulos públicos no Brasil, a política de taxas de juros elevadas e a alta participação dos títulos indexados à taxa de juros básica tem causado efeitos contraditórios. Conforme visto, as estratégias relativas à troca de títulos pósfixados por títulos prefixados, em busca da ampliação do prazo médio e da redução dos riscos para o setor público, são realizadas por meio do patamar de juros presente, o que mantém, assim, o alto custo de financiamento associado à dívida pública e as restrições quanto à atuação da política fiscal. Tal patamar dos juros pode implicar uma rigidez nominal dos juros para baixo enquanto os prazos não forem significativamente alongados. $E$ enquanto não são, deve-se admitir uma condição de ceteris paribus no cenário econômico internacional para que enfim ocorram.

\section{Política fiscal sob restrições financeiras persistentes}

Da análise nas seções precedentes, encontra-se três aspectos que definem as restrições da administração da dívida pública. Primeiro, a dívida mobiliária como razão do produto cresceu a partir de 1995 e passou a representar uma restrição à política de gastos públicos; segundo, o perfil da dívida não é facilmente expandido, restringido o financiamento ao curto/médio prazo; e, terceiro, a manutenção da taxa de juros elevada decorrente da política de administração da dívida pública criou uma rigidez para baixo da taxa de juros e impôs uma restrição ao aumento da poupança do próprio governo.

$\mathrm{Na}$ dimensão dos gastos não financeiros, observa-se uma outra forma de restrição, compreendida com o congelamento dos gastos tanto em infraestrutura quanto em políticas sociais. $\mathrm{Na}$ Tabela 3 , apresenta-se os valores das despesas do governo por função a preços de 2008.

Primeiramente, dentre os gastos associados à área social, é importante salientar que tais desembolsos se apresentam altamente concentrados em despesas referentes à seguridade social, ou seja, à saúde, à assistência social e, principalmente, à previdência social. Os gastos públicos com previdência social vêm sendo amplamente criticados em função da trajetória crescente que apresentam. A crítica isolada a essa função não é correta, visto que, como esclarecem Gentil (2007), Passarinho (2007) e Marques (2007), diante do conceito de seguridade social deveriam ser consideradas, além das receitas dos contribuintes, outras receitas provenientes do orçamento da seguridade 
social, como receitas da Contribuição Social sobre o Lucro Líquido (CSLL), da Contribuição para o Financiamento da Seguridade Social (Cofins), o que descaracterizaria seu suposto viés deficitário. ${ }^{23}$

As despesas com encargos especiais, que englobam os custos relativos ao refinanciamento da dívida pública, tanto externa quanto interna, mais seus encargos financeiros, representaram mais da metade dos gastos do setor público consolidado por função. Em relação aos demais componentes de gastos, observa-se que ao longo dos últimos anos alguns desembolsos apresentaram taxa de crescimento negativa, como os gastos com cultura, saneamento básico e transportes.

Tabela 3 - Despesas do Setor Público Consolidado por Função - Brasil (em $\mathrm{R} \$ 1.000 .000$ )*

\begin{tabular}{l|r|r|r|r|r}
\hline \multicolumn{1}{c|}{ Função } & \multicolumn{1}{c|}{2002} & \multicolumn{1}{c|}{2003} & \multicolumn{1}{c|}{2004} & \multicolumn{1}{c}{2005} & \multicolumn{1}{c}{2006} \\
\hline Legislativa & \multicolumn{1}{c|}{$15.514,63$} & $15.926,95$ & $15.671,18$ & \multicolumn{1}{c}{$15.819,49$} & \multicolumn{1}{c}{$17.680,26$} \\
\hline Judiciária & $30.121,17$ & $28.534,71$ & $29.024,17$ & $30.339,11$ & $34.853,12$ \\
\hline Essencial à Justiça & $5.102,29$ & $5.156,37$ & $7.070,10$ & $7.647,77$ & $8.922,02$ \\
\hline Administração & $50.148,79$ & $46.150,02$ & $49.164,23$ & $47.553,85$ & $53.381,95$ \\
\hline Defesa N acional & $28.782,38$ & $15.513,99$ & $16.589,23$ & $19.220,48$ & $18.866,91$ \\
\hline Segurança Pública & $26.998,75$ & $30.232,95$ & $28.489,26$ & $30.719,63$ & $36.105,40$ \\
\hline Relações Exteriores & $2.812,25$ & $1.568,82$ & $1.665,82$ & $1.769,89$ & $1.555,69$ \\
\hline Assistência Social & $21.238,01$ & $18.846,61$ & $23.150,46$ & $24.867,75$ & $32.271,90$ \\
\hline Previdência Social & $238.985,48$ & $225.522,47$ & $238.901,08$ & $254.907,84$ & $284.347,10$ \\
\hline Saúde & $90.147,52$ & $94.867,36$ & $102.858,67$ & $106.899,51$ & $120.865,51$ \\
\hline Trabalho & $34.231,25$ & $13.895,33$ & $14.201,83$ & $15.866,15$ & $19.920,35$ \\
\hline Educação & $92.253,63$ & $107.949,66$ & $98.548,54$ & $101.778,17$ & $114.895,35$ \\
\hline Cultura & $3.973,17$ & $2.852,92$ & $2.740,19$ & $3.218,51$ & $3.916,81$ \\
\hline Direitos da Cidadania & $2.162,97$ & $2.982,65$ & $3.368,89$ & $3.842,83$ & $4.633,66$ \\
\hline
\end{tabular}

${ }^{23}$ Conforme Gentil (2007), Passarinho (2007) e Marques (2007), o que se denomina déficit da previdência, na verdade, seria o saldo previdenciário negativo, que diz respeito ao somatório das contribuições sobre a folha de salários, subtraído pelos benefícios previdenciários do Regime Geral de Previdência Social (RGPS). Ao se considerar somente esses valores, o déficit previdenciário realmente existe e se apresenta crescente ao longo dos últimos anos. Porém, a partir da Constituição de 1988, o regime de previdência social passa a ser entendido como um sistema amplo de seguridade social, composto por previdência, saúde e assistência social. Assim, quando se consideram os resultados relativos à previdência social e a seus benefícios, devem ser consideradas as receitas provenientes do orçamento de seguridade social, e não apenas as receitas dos contribuintes previdenciários. 


\begin{tabular}{l|r|r|r|r|r}
\hline Urbanismo & $20.330,37$ & $19.680,87$ & $20.842,76$ & $18.786,33$ & $24.269,60$ \\
\hline Habitação & $2.381,74$ & $2.185,57$ & $2.862,60$ & $3.213,26$ & $4.026,39$ \\
\hline Saneamento & $9.562,93$ & $7.229,31$ & $6.660,49$ & $6.412,79$ & $8.643,73$ \\
\hline G estão A mbiental & $5.562,28$ & $4.793,55$ & $4.674,09$ & $5.394,51$ & $5.105,53$ \\
\hline Ciência e Tecnologia & $3.747,19$ & $3.978,58$ & $4.668,13$ & $5.444,83$ & $6.020,11$ \\
\hline A gricultura & $13.486,65$ & $13.078,92$ & $13.364,62$ & $14.108,24$ & $16.228,53$ \\
\hline O rganização A grária & $2.455,97$ & $2.047,90$ & $3.359,79$ & $4.305,70$ & $4.933,25$ \\
\hline Indústria & $3.369,86$ & $2.191,06$ & $2.998,94$ & $3.134,26$ & $3.754,64$ \\
\hline Comércio e Serviços & $5.866,92$ & $5.060,49$ & $4.168,32$ & $4.924,34$ & $5.107,08$ \\
\hline Comunicações & $6.010,39$ & $1.298,78$ & $1.189,18$ & $1.098,21$ & $1.148,27$ \\
\hline Energia & $13.695,57$ & $6.375,02$ & $1.628,19$ & $2.025,20$ & $3.045,13$ \\
\hline Transporte & $47.189,02$ & $19.192,57$ & $21.607,11$ & $26.515,05$ & $27.139,65$ \\
\hline Desporto e Lazer & $2.050,75$ & $1.875,93$ & $2.001,73$ & $2.088,28$ & $3.199,38$ \\
\hline Encargos Especiais & $778.038,39$ & $905.675,44$ & $822.974,97$ & $964.177,77$ & $979.604,24$ \\
\hline Total & $1.556 .220,34$ & $1.604 .664,77$ & $1.544 .804,58$ & $1.726 .099,78$ & $1.844 .441,55$ \\
\hline Orç̧amento & & &
\end{tabular}

* Orçamento Fiscal e da Seguridade Social. Valores em abril de 2008, atualizados pelo IGP-DI.

Fonte: Secretaria do Tesouro Nacional (BRASIL, 2007c).

Como forma de minimizar tais dificuldades, o governo brasileiro procurou adotar medidas com o intuito de contornar os obstáculos impostos aos gastos com políticas sociais e infraestrutura. 0 Programa de Aceleração do Crescimento (PAC), lançado pelo governo federal em 2007, tem previsão de gastos da ordem de R\$503 bilhões em investimentos público e privado para o período 20072010. Desse valor, R\$ 67 bilhões seriam correspondentes ao orçamento fiscal e $R \$ 436$ bilhões seriam de responsabilidade dos orçamentos das empresas estatais e da iniciativa privada.

Notadamente em relação aos investimentos em infraestrutura, por meio da rubrica do Projeto Piloto de Investimento (PPI), o PAC propôs, para 2007, investimentos públicos de $\mathrm{R} \$ 11,3$ bilhões, dos quais seriam descontados do cálculo de metas de superávit primário. Em outras palavras, com uma meta de superávit primário de $R \$$ 53 bilhões, o Governo Central (União, Previdência e Banco Central) poderia descontar até $\mathrm{R} \$ 11,3$ bilhões referentes ao $\mathrm{PPI}^{24}$ (Quadro 2). Para 2008, a previsão de gastos chega a $\mathrm{R} \$ 13,8$ bilhões.

\footnotetext{
24 Inicialmente, a LDO 2007 previa um abatimento sobre o superávit primário de $\mathrm{R} \$ 4,6$ bilhões para atender ao PPI. A pós sofrer alteração com o PAC, o valor para o PPI passou a $\mathrm{R} \$ 11,3$ bilhões.
} 
Quadro 2 - Lei de Responsabilidade Fiscal, Metas F iscais e Projeto Piloto de Investimento - Brasil (2007)

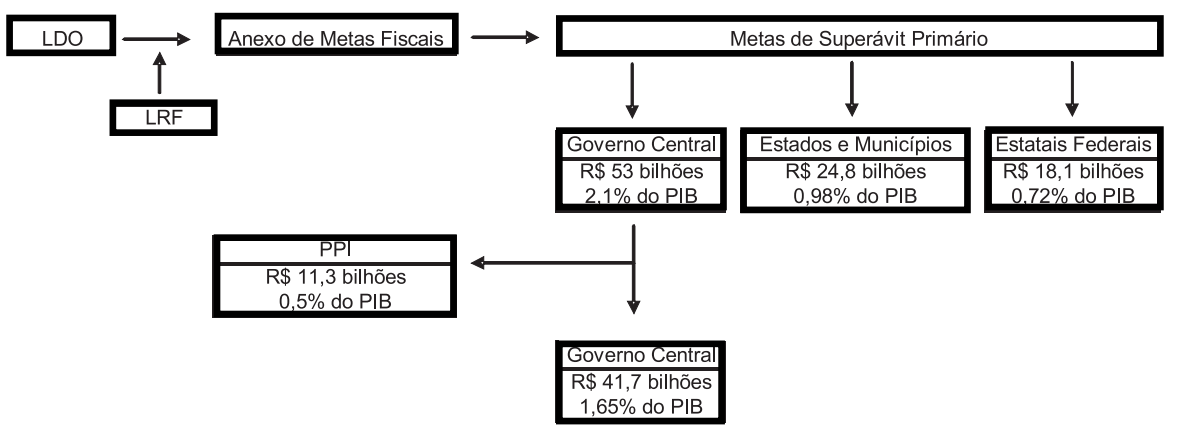

Fonte: Elaboração Própria

Através do PAC e do PPI, foi possível observar uma maior preocupação por parte do setor público quanto à utilização de uma política fiscal ativa, conforme sustenta a política econômica keynesiana em cenários de desemprego. Por meio da política fiscal, haveria um incentivo a um ambiente econômico favorável para a atuação do setor privado. Nesse aspecto, o PAC e o PPI poderiam colaborar tanto para a geração de expectativas favoráveis quanto para a expansão da atividade econômica, através do efeito do multiplicador de renda e dos benefícios gerados por investimentos em infraestrutura.

O pensamento keynesiano sustenta uma política fiscal ativa de aumento dos gastos públicos, principalmente em investimentos públicos, no sentido de garantir um ambiente favorável para a atuação do setor privado. ${ }^{25}$ Assim, o PAC poderia contribuir para um debate mais consistente em relação à política fiscal no País. De acordo com Sicsú (2007, p.95):

Um ponto crucial do programa foi a ampliação do escopo da política fiscal que tinha o restrito objetivo de tão-somente reduzir a relação dívida/PIB. A política fiscal do PAC visa também à promoção do crescimento econômico, um objetivo consagrado pelas políticas fiscais keynesianas nos anos de ouro do capitalismo durante o século XX.

${ }^{25}$ Para detalhes sobre a política fiscal keynesiana, ver Carvalho (2007) e Kregel (1985). 
No entanto, frente à política econômica do período analisado, constatou-se uma postura inconsistente em relação aos objetivos do PAC e de uma política fiscal ativa. Como resultado do plano, entre janeiro e maio de 2007, foram gastos apenas $R \$ 990$ milhões. O baixo volume de gastos com investimentos públicos mostrou que, apesar da preocupação com projetos que melhorassem a infraestrutura e proporcionassem um maior crescimento econômico, o Estado brasileiro continua com grandes restrições quanto a uma atuação que fortaleça o movimento ascendente da taxa de crescimento.

A evidência da redução dos investimentos em infraestrutura é incompatível com os planos de crescimento. A geração de superávits primários reduz o grau de liberdade da política econômica e impossibilita a existência de uma política fiscal em sintonia com as flutuações econômicas.

Sob esse quadro de redução de gastos não financeiros e geração de significativos superávits primários, o nível de arrecadação do setor público teve de se manter elevado, o que fez com que a carga tributária, principal fonte de financiamento público no contexto da política fiscal instituída, apresentasse uma trajetória crescente ao longo dos últimos anos. Verificou-se que a partir de 1999 a carga fiscal cresceu mais acentuadamente (Gráfico 3). Entre 1995 e 1998, o nível de impostos manteve-se praticamente estável, em torno de $26 \%$ do PIB, com um aumento da participação das contribuições, ${ }^{26}$ de modo a garantir um maior grau de liberdade para a utilização dos impostos no pagamento das despesas financeiras. A partir de 1999/2000, com a garantia da LRF, o caráter crescente dos impostos se tornou evidente, uma vez que, diante do aumento das despesas financeiras no período 1995-1998, o governo elevou a arrecadação e o superávit primário com o objetivo de evitar um crescimento crônico do déficit nominal.

Em relação à carga tributária no Brasil, Sicsú (2007, p.95) acrescenta:

Ela foi aumentada exatamente durante os últimos governos de $\mathrm{FHC}$ e Lula com o objetivo de reduzir o déficit nominal que cresceria de forma

\footnotetext{
${ }^{26}$ As contribuições são imposições tributárias que concedem o direito a alguma contrapartida, ou seja, são arrecadados para determinado fim, como as contribuições previdenciárias, utilizadas para financiar os gastos com seguridade social (GIAMBIAGI; ALÉM, 2000). O aumento da participação das contribuições se tornou necessária no sentido de contribuir para a maior utilização dos impostos para o pagamento de juros nominais.
} 
explosiva por conta das elevadas despesas financeiras do governo, decorrentes das altas taxas de juros praticadas durante esse período. A causa da elevação da carga tributária foi o aumento da taxa de juros básica da economia. Esqueceram de dizer que países com grau de desenvolvimento semeIhante ao do Brasil praticam uma taxa de juros bem menor que a nossa e suas dívidas públicas não são indexadas à taxa básica de juros, o que, portanto, Ihes permite ter uma carga tributária menor.

Gráfico 3 - Carga Tributária em \% do PIB

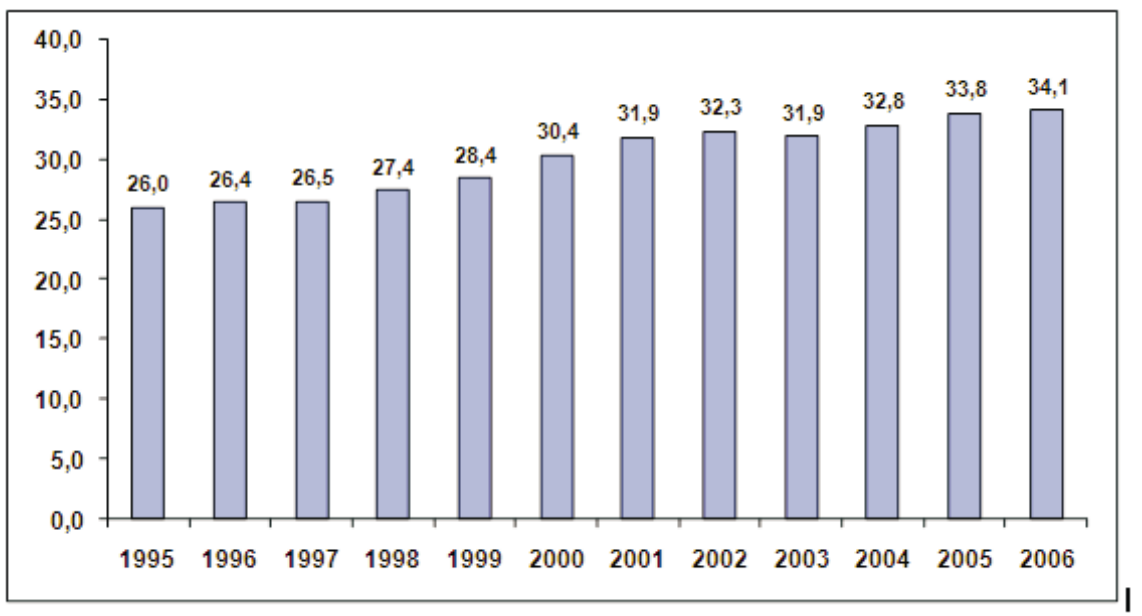

Fonte: IPEADATA, 2007

O aumento da carga tributária no Brasil não se justificaria pelo aumento das despesas com políticas sociais e com infraestrutura, mas sim, pela necessidade de se evitar um aumento crônico do déficit público nominal resultante, em grande parte, dos encargos financeiros de uma dívida pública indexada à taxa de juros básica.

Em suma, a política econômica adotada recentemente no País, caracterizada por uma política de juros elevados e por uma composição e perfil de endividamento público desfavoráveis, compromete a atuação de uma política fiscal ativa, e de uma política consistente com o crescimento da produtividade e da renda. Tendo em vista o valor das despesas financeiras, o setor público incrementa o patamar de seu superávit primário através de uma carga tributária elevada e de uma rigidez em relação aos gastos públicos não financeiros, que afetam negativamente a produção de curto prazo e a perspectiva de novos investimentos. À despeito da geração de superávits primários, 
a magnitude dos gastos financeiros ainda sustenta déficits nominais da ordem de $2 \%$ a $3 \%$ do PIB.

\section{Considerações finais}

0 artigo procurou explorar a tensão criada pela política de financiamento da dívida pública e pela constante geração de superávits primários elevados. Apesar do esforço de arrecadação e do congelamento dos gastos não financeiros, que assim colaboraram para um maior ajuste das contas do setor público, os gastos com previdência social continuam a ser criticados. Em tese foi o valor social que se imputou à noção de seguridade que tem sido criticada sistematicamente, em favor da manutenção de uma transferência de riqueza para credores do setor público.

A discrepância em relação ao destino do orçamento público para as despesas financeiras em detrimento das despesas não financeiras se manifesta na geração de déficits nominais persistentes, que ainda não são alvo de maior importância pelos formuladores de política econômica, nem mesmo após o contorno institucional dado pela LRF.

A LRF, criada para reduzir a pressão sobre os gastos públicos e para prevenir a irresponsabilidade em relação às contas públicas, junto com a mudança do regime de política fiscal a partir de 1999, deixou de incluir como foco os desembolsos com despesas financeiras e a atual estrutura de endividamento do setor público. É uma interpretação assimétrica em termos de responsabilidade fiscal, uma vez que, se limita aos aspectos da arrecadação e dispêndio não financeiro, não obstante ao cenário e a redução de regras e regulamentações que ocorreram nos mercados financeiros.

J uros altos, despesas financeiras elevadas e superávits primários obtidos através do aumento da carga tributária e do congelamento dos gastos públicos não financeiros, em particular em infraestrutura, representam, portanto, um nonsense ao que se idealiza com um ambiente favorável aos investimentos produtivos. Diante de uma rígida estrutura de alguns componentes de gastos sociais, como com previdência social, o ajuste de gastos públicos se dá, principalmente, por meio das despesas com investimentos públicos, como a partir do baixo volume desembolsado com o Programa de Aceleração do Crescimento (PAC) e com o Projeto Piloto de Investimento (PPI).

O PAC e o PPI tendem a contribuir para a atuação efetiva da política fiscal, à medida que garantem recursos para o setor público, 
investir em projetos de infraestrutura, e, por conseguinte, complementar e contribuir para a atuação dos investimentos privados, conforme sustenta a política econômica keynesiana. No entanto, ao invés de impulsionar projetos de investimentos e possibilitar algum grau de liberdade à política fiscal, o setor público intensifica a realização de superávits primários e prejudica o desenvolvimento econômico do país em prol dos elevados encargos financeiros da dívida. Os investimentos públicos e os projetos de infraestrutura tornam-se, portanto, variáveis residuais diante do objetivo maior de garantir a realização do superávit primário.

A fim de buscar um debate mais apropriado em relação à utilização da política fiscal como instrumento de política econômica, torna-se necessário modificar a atual estrutura de financiamento/ endividamento. Uma melhor estrutura da dívida pública, aliado a uma política de juros menos restritiva, contribuiria para a redução das despesas financeiras, do superávit primário e para a geração de resultados nominais equilibrados.

O período de 2002 a 2006 apresentou as condições para a economia brasileira se expandir e, ao governo, a condição do alongamento da dívida pública a um custo menor, comparativamente ao período anterior. A sustentação da condição fiscal, no entanto, não foi substancialmente alterada, deixando uma perspectiva de que frente a choques, os ajustes recairão novamente sobre o emprego e a renda mais do que o necessário, caso as restrições apontadas neste artigo fossem reduzidas nas condições favoráveis no período recente.

A dinamização do PAC e do PPI tem a condição de expandir a renda e a arrecadação tributária, ao contrário da lógica persistente de produzir um superávit primário que, ao limitar a política fiscal, retiram a possibilidade de expandir a demanda agregada.

\section{Referências}

ARESTIS, P.; PAULA, L. F.; FERRARI FILHO, F. Inflation targeting in emerging countries: the case of Brazil. In: Encontro Nacional de Economia, 34. Salvador, 2006. A nais... Salvador: ANPEC, 2006. p.1-20.

BACHA, E. Plano Real: uma segunda avaliação. In: IPEA/CEPAL. O Plano Real e outras experiências internacionais de estabilização. Brasília, 1997. p.177-202.

BANCO CENTRAL DO BRASIL. Boletins Anuais. Disponível em: http://www.bc.gov.br. Acesso em: 20/01/2007.

BRASIL. Lei Complementar N . 101 de 04 de maio de 2000. Disponível em: < http://www.stn. fazenda.gov.br/legislacao/download/contabilidade/lei_comp_101_00.pdf > . Acesso em: 20 jul. 2007. 
BRASIL. Lei de Diretrizes Orçamentárias de 2007. Anexo IV.1 - Anexo de M etas Anuais. Disponível em: <http://www.planejamento.gov.br/arquivos_down/sof/lei/ldo_11439_ 061229_anexos/LDO_11439_061229_AnexolV.pdf> . A cesso em: 20 jul. 2007a.

BRASIL. Ministério do Planejamento. Disponível em: <www.planejamento.gov.br> Acesso em: 17 jul. 2007b.

BRASIL. SECRETARIA DO TESOURO NACIONAL. Disponível em: <http://www.tesouro. fazenda.gov.br>. Acesso em: 20 jan. 2007c.

BRASIL. SECRETARIA DO TESOURO NACIONAL. Relatório Mensal da Dívida Pública Federal (vários números). Disponível em: < http://www.tesouro.fazenda.gov.br > . Acesso em: 20 jan. 2007d.

CARNEIRO, R. Desenvolvimento em crise: a economia brasileira no último quarto do século XX. São Paulo: UNESP, IE/Unicamp, 2002.

CARVALHO, F. J . C. Equilíbrio fiscal e política econômica keynesiana. Disponível em: <www.ie.ufrj.br/moeda/pdfs/equilibriofiscal.pdf>. A cesso em: 10 ago. 2007.

CASTRO, J . A. et al. Gasto social federal em uma dimensão macroeconômica: 19952001. In: PINTO, M. P. A.; BIASOTO J r., G. (O rg.). Política fiscal e desenvolvimento no Brasil. Campinas: Ed. Unicamp, 2006. p.137-172.

CASTRO, L. B. Privatização, abertura e desindexação: a primeira metade dos anos 90 (1990-1994). In: GIAMBIAGI, F., et al. (Org.). Economia brasileira contemporânea: 19452004. Rio de J aneiro: Campus, 2005. p.141-165.

FERRARI FILHO, F. Da tríade mobilidade de capital, flexibilidade cambial e metas de inflação à proposição de uma agenda econômica alternativa: uma estratégia de desenvolvimento para a economia brasileira à luz da teoria pós-keynesiana. Porto Alegre: UFRGS, 2002. (Texto de Discussão).

O legado do Plano Real: uma estabilização sem crescimento econômico. Revistà Análise Econômica, Porto Alegre, ano 19, n. 35, p.5-21, mar. 2001.

FRANCO, G. O Plano Real e outros ensaios. Rio de J aneiro: F. Alves, 1995.

GIAMBIAGI, F.; ALÉM, A. C. Finanças públicas: teoria e prática no Brasil. 2 ed. São Paulo: Campus, 2000.

GENTIL, D. L. A política fiscal e a falsa crise da seguridade social no Brasil: análise financeira do período recente. In: SICSÚ, J . (Org.) Arrecadação (de onde vem?) e gastos públicos (para onde vão?). São Paulo: Boitempo, 2007. p.29-35.

IPEADATA. Disponível em: http://www.ipeadata.gov.br/. Acesso em: 13 jan. 2007.

KEYNES, J ohn Maynard. The collected writings of J ohn Maynard Keynes. London: Macmillan, 1971. v.13.

KHAIR, A. A. A questão fiscal e a lei de responsabilidade fiscal. In: PINTO, M. P. A.; BIASOTO J r., G. (Org.). Política fiscal edesenvolvimento no Brasil. Campinas: Ed. Unicamp, 2006. p.343-370.

KREGEL, J . Budget deficits, stabilization policy and liquidity preference: Keynes's postwar policy proposals. In: VICARELLI, F. (Ed.). Keynes's relevancetoday. Londres: Macmillan, 1985. p.28-50.

MARQUES, R. M. Uma Previdência Social para os brasileiros. In: SICSÚ, J . (Org.). Arrecadação (de onde vem?) e gastos públicos (para onde vão?). São Paulo: Boitempo, 2007, p.17-27.

MOURA, A. R. Dívida pública interna: os estrangeiros estão chegando. Revista Conjuntura Econômica, São Paulo, v.61, n.03, p.12-13, mar. 2007. 
PASSARINHO, P. Previdência Social Pública: um serviço universal ao cidadão brasileiro. In: SICSÚ, J . (O rg.). Arrecadação (de onde vem?) e gastos públicos (para onde vão?). São Paulo: Boitempo, 2007. p.37-49.

RIBEIRO, A. Capital externo compra mais título do tesouro. Valor Econômico, São Paulo, p.A 1, 25 abr. 2007.

SICSÚ, J. PAC: quatro anos depois o governo tenta mudar o rumo. In: SICSÚ, J. (Org.). Arrecadação (de onde vem?) e gastos públicos (para onde vão?). São Paulo: Boitempo, 2007. p.93-97.

SICSÚ, J .; VIDOTTO, C. A administração fiscal no Brasil e a taxa de juros. In: SICSÚ, J . (Org.). Arrecadação (de onde vem?) e gastos públicos (para onde vão?). São Paulo: Boitempo, 2007. p. 111-119.

TAVARES, M. C. A economia política do real. In: MERCADANTE, A. (Org.). O Brasil pós Real: a política econômica em debate. Campinas: Unicamp, 1998. 